\title{
Possibilidades de elaboração do desamparo infantil através do brincar
}

\author{
Possibilities of elaborating child neglect through play \\ Jéssica Carvalho de Oliveira ${ }^{* *}$, Michele Mariana Vieira Ferreira Santos ${ }^{\star}$
}

Como citar esse artigo. de Oliveira, J.C.; Santos, M.M.V.F. Possibilidades de elaboração do desamparo infantil através do brincar. Revista Mosaico $2019 \mathrm{Jul}$ Dez.; 10 (2): SUPLEMENTO 89-95

\author{
Resumo
}

O objetivo deste artigo é trazer a importância do brincar como recurso terapêutico, favorecendo a comunicação entre criança e analista, além de propiciar a elaboração do sentimento de angústia do desamparo. Tendo a psicanálise como base teórica, foi levantada a questão da importância do meio em que a criança está inserida, sendo este compreendido pela função materna ou figura de cuidado, além de propiciar levantamentos teóricos diante do desamparo, relação mãe-bebê e a importância de uma "mãe suficientemente boa" para o desenvolvimento infantil. A partir de revisão da literatura, conclui-se que o brincar torna-se ferramenta imprescindível na clínica com crianças, uma vez que ele se revela como instrumento benéfico para elaboração de traumas e ansiedades.

Palavras-chave: Brincar; Criança; Desamparo; Elaboração.

\begin{abstract}
The aim of this article is to bring the importance of play as a therapeutic resource, favoring the communication between child and analyst, besides providing the elaboration of the feeling of anguish of helplessness. Having psychoanalysis as a theoretical basis, the question of the importance of the environment in which the child is inserted was raised, which is understood by the maternal function or figure of care, besides providing theoretical surveys in the face of helplessness, mother-baby relationship and the importance of a "good enough mother" for child development. From the literature review, it is concluded that playing becomes an indispensable tool in the clinic with children, since it is a beneficial tool for the elaboration of trauma and anxieties.

Keywords: child, helplessness, elaboration, play.
\end{abstract}

\section{Introdução}

O brincar é considerado uma ferramenta de muita relevância para o processo terapêutico na clínica com crianças. Durante o momento lúdico dentro do setting é possível observar que a criança se expressa através dos brinquedos, dando oportunidade da mesma projetar seus desejos, fantasias e conflitos. Considera-se que todo contexto familiar em que a criança está inserida, tende a aparecer em algum momento durante as brincadeiras, isso se dá, porque a brincadeira passa a ser muito mais do que apenas um entretenimento infantil, mas uma ferramenta de desenvolvimento emocional e um mecanismo de comunicação com o profissional.

É comum nos atendimentos psicanalíticos com crianças nos depararmos com diversas situações, dentre elas, o quanto a criança repete no brincar experiências vivenciadas com as pessoas e meios como a escola, em casa ou outros lugares por onde circula, dentre elas, situações que são conflituosas e muitas vezes causadoras de angústia.

Para a psicanálise, as primeiras relações na vida de um bebê são muito significativas para o seu desenvolvimento. Todos os cuidados da mãe ou de algum objeto protetor que realize essa função fazem com que a criança se sinta amparada, de modo que sempre haverá alguém que realize suas satisfações, uma relação considerada fundamental para as fases de desenvolvimento da criança e da sua construção psíquica.

Sendo assim, a partir das experiências durante os atendimentos clínicos com crianças nos estágios

Afiliação dos autores: $\uparrow$ Graduanda do Curso de Psicologia, Universidade de Vassouras, Vassouras, RJ, Brasil

¥ Mestre em Psicologia, Curso de Psicologia, Universidade de Vassouras, Vassouras, RJ, Brasil

* Email de correspondencia: jessica_carvalhomp@hotmail.com 
realizados, é possível levantar a questão de que a criança projeta sua angústia de desamparo no brincar, muitas vezes, resultado da ausência ou separação de alguém que forneça cuidados necessários e amor.

Cabe ressaltar, que a impotência do bebê em lidar com algumas situações que causam angústia e medo diante de possíveis separações, faz com que ele vivencie o sentimento de desamparo, resultado de um temor ao abandono e de um carecimento do objeto que atende às suas necessidades, não apenas de alimentação e cuidados básicos, mas também a necessidades emocionais, como afeto, amor e atenção. Como exemplo, podemos citar uma criança que está no meio de um conflito de separação dos pais, ou aquela que mesmo com os cuidados da função materna, sente a insuficiência e falta de um pai que não disponibiliza atenção. É importante considerarmos que o sentir é muito subjetivo de cada um, e sendo assim, cada criança poderá lidar de formas diferentes com essas situações.

O presente trabalho busca promover reflexões acerca da importância do brincar no processo de elaboração de situações traumáticas ou frustrações provenientes da falta de alguém que forneça cuidado. A partir desse contexto, debruçaremos sobre as teorias do psicanalista Donald Woods Winnicot, visando compreender a importância do meio em que a criança está inserida e se constitui meio este que é compreendido pela mãe ou outra pessoa que realize a função materna. Além disso, também nos deteremos ao conceito de uma "mãe suficientemente boa" posto como possibilidade para a criança lidar com a falta e frustrações de modo saudável.

A revisão de literatura se dará com base nas abordagens em torno da psicanálise, acerca do desamparo frente à relação mãe-bebê, compreendido a partir da obra freudiana do Complexo de Édipo, e nos conceitos da psicanálise infantil pautada nas obras de Melanie Klein, Donald Winnicot, Terezinha Costa, Maud Mannoni e Arminda Aberastury.

Sendo assim, através de literatura especializada, o objetivo é tecer alguma compreensão acerca da importância do brincar em um processo de elaboração de situações traumáticas e experiências vivenciadas pela criança, situações essas que podem remeter ao sentimento da angústia de desamparo. E, para abordar isso, levaremos em consideração o atual cenário da família contemporânea, em que é cada vez mais presente o distanciamento da criança em relação aos pais ou de alguém que realize essa função.

\section{Considerações acerca do desamparo}

A proposta de trazer entendimentos sobre o desamparo é evidenciar o sentimento gerado na criança ao temer uma perda ou separação de seu objeto protetor, àquele que tende a abastar satisfações no qual ele necessita.

Segundo Resstel (2015), o desamparo pode ser compreendido como um sentimento de abandono, insegurança, uma incapacidade de lidar com situações consideradas difíceis. É necessário que a figura de cuidado interprete as necessidades da criança pequena para conseguir atendê-las, fazendo com que uma comunicação seja estabelecida entre ela e o mundo externo.

Segundo Laplanche e Pontalis (2001), a respeito do desamparo:

Termo da linguagem comum que assumeum sentidoespecífico na teoria freudiana. Estado do lactente que, dependendo inteiramente de outrem para a satisfação das suas necessidades (sede, fome), é impotente para realizar a ação específica adequada para pôr fim à tensão interna. Para o adulto, o estado de desamparo é o protótipo da situação traumática geradora de angústia. (LAPLANCHE; PONTALIS, 2001, p. 112)

Podemos também fazer uma associação entre o desamparo e o temor à castração, para isso buscamos entender o complexo de Édipo proposto por Freud, com objetivo de compreender a relação da figura materna e do bebê, onde a mãe é o primeiro objeto de amor da criança, ou seja, as fantasias da criança estão totalmente interligadas à figura materna. Através dessa obra é possível perceber alguns sentimentos da criança com relação às figuras parentais.

Costa (2010a) destaca que inicialmente o objeto de amor do menino é a mãe, ela é seu objeto de desejo, e ele tende a ver a figura paterna como seu rival, acha que o pai é alguém que concorre pelo amor da mãe. Dessa forma, posteriormente ele irá ser ameaçado pela castração através de seu pai, que tende a representar a lei, o interdito, ou seja, ele acredita que se continuar obtendo a mãe como objeto de desejo, irá perder seu pênis.

Esse fato tende a provocar angústia, pois o menino "renuncia" o seu desejado objeto de amor para preservar o pênis que havia sido repreendido pela castração. A partir daí o menino passa a criar uma identificação com o pai e se inicia o período de latência.

Segundo a autora, nas meninas, o que ocorre é que a mãe também é vista inicialmente como objeto de amor, mas posteriormente seu direcionamento pulsional é voltado para o pai. A menina se depara com a diferença anatômica em relação ao menino, e por isso, acredita ter sido castrada, já que não compreende a ausência do pênis.

Diferentemente de Freud, Melanie Klein acredita que todo o processo edípico já se inicia a partir do desmame, entre os dois ou três meses, o que ela chama de Édipo primitivo. Klein argumenta que tanto o menino quanto a menina se distanciam da mãe nesse período do desmame porque ela é a portadora do seio que os 
satisfaz, e esse desmame tende a resultar em um grande trauma. (COSTA, 2010a)

Na abordagem de Klein, a mãe tende a ocupar um lugar de grande importância na vida da criança, segundo ela é origem de conforto, alimento e vida. Conforme a autora, a compreensão de que o desmame é considerado um grande trauma, infere-se que este tende a gerar um grande sentimento de angústia no bebê (COSTA, 2010b). Isso se dá devido ao fato de que o desmame é basicamente uma separação de corpo entre a criança e figura materna, afinal de contas o seio é o objeto de desejo.

Ainda com Costa (2010a), além do trauma referente ao desmame, Klein aborda que a experiência do nascimento tem grande influência nas relações do bebê com o mundo externo, pois a perda do estado intrauterino ocasiona uma grande agressão ao bebê. Nesse caso, a ideia kleiniana se assemelha de Freud, na qual ele pontua que o momento do nascimento é identificado como um grande trauma, considerando que no ato do nascimento, ao se separar da mãe, a criança sofre a primeira experiência de desamparo.

Para esses autores, a importância de entender o Complexo de Édipo se dá aqui a partir da possibilidade do sentimento de desamparo descrito acima ser remetido ao medo da castração, ou seja, o medo de perder o pênis é assemelhado a um sentimento de desamparo.

\section{A dependência mãe-bebê a partir de Winnicot}

O meio em que a criança está inserida tem grande significado para seu desenvolvimento, tanto psíquico quando físico. Este ambiente pode ser representado pela função materna, podendo fornecer à criança todo o conhecimento de mundo, enquanto oferece os cuidados necessários para sua vida inicial. (COSTA, 2010b).

A mãe colabora para que a criança tenha conhecimento do mundo exterior e se adapte de acordo com suas necessidades. A partir desse contexto, podese afirmar que todos os apoios que a criança recebe na infância são fundamentais, e a afetividade que lhe é transmitida faz com que a criança se desenvolva física e psiquicamente.

Para melhor compreensão, Costa (2010b) argumenta que segundo Winnicot, a criança irá se desprendendo deste ambiente até alcançar independência. Ele realizou uma divisão em que a fase inicial era àquela que se dá entre o nascimento e os seis meses de vida, nessa fase a criança se encontra em dependência absoluta de alguém que a forneça cuidados, de um objeto protetor. A criança na fase de dependência absoluta necessita exclusivamente da mãe ou alguém que faça essa função. Um fator de grande importância deste período, é que o bebê desconhece esse estado de dependência, ele não consegue fazer a diferenciação entre ele e o meio.

Ainda de acordo com Costa (2010b), a segunda fase descrita por Winnicot é a fase que vai dos seis meses de idade até os dois anos, onde a criança se encontra em estado de dependência relativa. Nessa fase, a criança já percebe objetos externos e outras pessoas, começando a identificar que ela e a mãe são separadas.

Diante disso, o bebê consegue identificar que necessita da mãe para que suas necessidades sejam atendidas, e vai se adaptando e desenvolvendo física e psiquicamente. A mãe/figura de cuidado que consegue atender às satisfações do bebê, mas que ao mesmo tempo vai deixando aos poucos de atendê-lo, é nomeada por Winnicot como a "mãe suficientemente boa", pois assim, ela colabora com que o bebê aprenda a lidar com a falta e frustrações. Dessa forma, a criança começa a compreender que mesmo esta função oferecendo cuidados ela também pode fracassar.

Costa (2010b) traz a noção de transicional a partir da teoria winnicottiana, que pode representar uma função ou um lugar e é classificado como o intermédio da criança e o mundo externo. Quando a criança leva a boca algum objeto, quando segura algum pedaço de pano, seus balbucios, por exemplo, são fenômenos transicionais, mas quando ele utiliza um objeto externo é denominado objeto transicional.

A utilização do objeto transicional faz com que a criança consiga lidar com a angústia, pois ele é repleto de significações, podendo até mesmo representar a mãe, ou seja, o objeto das primeiras relações do bebê. Ao decorrer do tempo, conforme a criança for conseguindo emitir sons, ela irá conseguir através de palavras designar um objeto transicional, que pode ser um ursinho ou qualquer outro brinquedo.

Nesse sentido, Franco (2003) levanta a questão de que para Winnicot, o brincar só poderá ser compreendido diante da noção de transicionalidade, onde os fenômenos transicionais são resultados do intermédio da realidade interna com a externa, podendo simbolizar a maternagem.

A criança utiliza do espaço transicional em todo seu desenvolvimento, esse espaço será ocupado pelo lúdico e o criativo. Cabe ressaltar, que isso só é possível com uma "mãe suficientemente boa".

Ao inferir sobre a maternagem suficientemente boa:

Winnicottressalta que estas atividades só se tornarão possíveis se houver uma maternagem suficientemente boa. A mãe identifica-se com o bebê e adapta-se às suas necessidades, permitindo que ele possa experimentar uma sensação de continuidade da vida e se desenvolver física e psiquicamente de acordo com suas tendências inatas. (COSTA, 2010b, p. 52)

Quando a mãe não consegue por algum motivo demandar as necessidades do filho, sendo falha no 
processo de adaptação, fazendo com que o bebê não consiga confiar nela, essa mãe é considerada por Winnicot como mãe insuficientemente boa. Nesse caso, podendo ser representada não somente por uma pessoa, mas também por alguma situação (NASIO, 1995).

É necessário que a mãe tenha função de holding, cujo papel fundamental é prestar sustentação à criança, deixando-a entrar em contato com a realidade externa, mas ao mesmo tempo impedindo que ocorra algum dano físico. O holding é basicamente o segurar, a sustentação física que a mãe fornece à criança na primeira infância, protegendo a mesma de algum tipo de dano fisiológico. Quando a função de holding é, de certa forma deficiente, a criança fica abalada emocionalmente, apresentando sentimento de angústia (SOUZA, 2010).

Ao tratar da prática psicanalítica da criança em setting terapêutico, Winnicot traz uma vasta colaboração, principalmente em casos em que a criança que teve certo insucesso em sua adaptação de necessidades. Pode-se considerar, que quando o profissional se depara com tal situação, o mesmo deverá exercer uma função de holding, ou seja, fornecendo um ambiente de sustentação e consequentemente tornando o atendimento agradável para a criança.

E, além disso, os objetos e fenômenos transicionais tendem a surgir diante da ameaça de uma cessação dos cuidados maternos. É através do objeto transicional que a criança consegue resistir e lidar com as faltas da separação materna. Nesse sentido, considera-se que quando ocorre uma falha na maternagem suficientemente boa, a criança se utiliza de objetos transicionais para que consiga suprir a falta. (COSTA, 2010b)

É na fase de dependência relativa que se torna fundamental os fenômenos transicionais, já que o bebê irá se adaptando a realidade externa. É considerado que toda essa relação entre realidade externa e interna da criança só se dá mediante um espaço transicional, espaço esse que tende a existir durante toda a vida, esse espaço será tomado pelo brincar.

Quando de alguma forma, a pessoa que representa a função materna se abstém dos cuidados devidos à criança, existe a possibilidade da mesma se deparar com a falta e o sentimento de angústia. Quando nos referimos a cuidados devidos, cabe ressaltar que não estamos nos relacionando apenas aos cuidados necessários para sobreviver, mas também ao amor, afeto e atenção.

No mundo contemporâneo, quando falamos em afastamento do objeto materno, não nos referimos apenas a negligência e abandonos, mas também ao novo cenário das famílias contemporâneas, onde cada vez mais cedo o cuidado das crianças é terceirizado e cada vez mais precocemente as mesmas saem de seu ambiente de acolhimento familiar, como por exemplo, a inclusão em creches, escolas e a ausência dos pais devido à carga horária de trabalho. Tudo isso tende a diminuir a frequência ou até mesmo a intensidade dos laços afetivos e suportes psíquicos.

Atualmente vivenciamos a fragilidade dos laços sociais, o tempo tem sido corrido diante das inúmeras coisas que as pessoas tentam dar conta, tudo isso vem acarretando influências diretas nas relações entre pais e filhos. Dessa forma, cada vez mais cedo à criança é levada a se deparar com a angústia da falta e ausência de um objeto protetor. Nesse momento, a pessoa que era sinônima de refúgio, atenção e amor, não estão abrindo mão de proporcionar os devidos cuidados, mas sim de estar atendendo as demandas do mundo contemporâneo.

\section{A importância do Brincar}

O brincar para a psicanálise teve a contribuição dos escritos de Freud na Obra Além do Princípio do Prazer, de 1920, em que após observar seu neto de um ano e seis meses brincando com um carretel de madeira fazendo movimentos que o fazia desaparecer e em seguida reaparecer, ele denominou de "Fort-da", isso porque cada vez que a criança soltava o carretel e o puxava, ele balbuciava fonemas. Este fato foi interpretado por ele sendo um jogo que a criança fazia para lidar com a falta da figura materna. (LAURENTINO; MELO, 2015). Dessa forma, isso nos leva a refletir a possibilidade que o brinquedo ou o simples ato de brincar se tornam ferramentas da clínica infantil importantíssimo para que a criança expresse suas fantasias, desejos e conflitos internos, proporcionando a criança lidar de forma sadia com a frustação.

Diante do jogo do "Fort da" denominado por Freud, é notório como a criança utiliza do brincar para controlar algum sentimento de angústia e desamparo, nesse caso, através do carretel o desconforto da ausência da mãe estava sendo elaborado. Partindo desse pressuposto, é considerado que a brincadeira de se esconder é a primeira forma da criança lidar com a falta e frustração diante da ausência da mãe (LAURENTINO; MELO, 2015).

Antes mesmo de Freud fazer a análise diante da brincadeira de seu neto, ele havia escrito o artigo "Recordar, Repetir e Elaborar", no qual terá grande relevância para o tema deste trabalho. Nesse sentido, a criança tem a possibilidade de recordar trazendo algum fato que está no seu psiquismo, não como lembrança, mas como ação, e assim repete, ou no contato com o profissional ou nas brincadeiras em si, para posteriormente vir a conseguir elaborar podendo ressignificar, dando espaço para compreensão dos significados (LEVINZON, 2010).

Durante os atendimentos com crianças, elas aproveitam o espaço e até mesmo a presença do profissional para conseguirem trazer seus desejos, fantasias e afetos resultados de experiências vivenciadas 
em casa, escola ou outro meio em que está inserida. A criança tende a repetir situações que remetem a perda ou separação de uma pessoa em que tinha ligação afetiva, repete conflitos presenciados e até mesmo a carência de uma figura materna (LEVINZON, 2010). Tudo isso pode ser observado pelo profissional através dos desenhos realizados pela criança, brincadeira com a família terapêutica, massinhas, entre outras ferramentas lúdicas.

O adulto consegue através de palavras trazer a queixa ao analista, já a criança transmite a demanda a ser trabalhada em análise por intermédio das brincadeiras. Nos atendimentos realizados com crianças durante os estágios, é possível observar que muitas das vezes elas não compreendem o motivo de estar ali, e nem se quer sabem a função de um psicólogo, elas chegam com a demanda dos pais, órgãos públicos, escolas, médicos entre outros. Diante disso, é crucial fazer com que ela se sinta à vontade no espaço, o analista deverá ocupar um lugar de "mãe suficientemente boa", conforme foi visto por Winnicot. Oferecer um ambiente suficientemente bom é fundamental para possibilitar que a criança se desenvolva criativamente através das brincadeiras.

Segundo os autores Simon e Yamamoto (2012), a contribuição de Klein no que se refere ao brincar na clínica psicanalítica com crianças é de grande relevância. Ao incluir os brinquedos na clínica, ela acredita alcançar o inconsciente das crianças, assemelhando-se ao método da associação livre na análise em adultos. Segundo eles:

A psicoterapia psicanalítica do adulto é feita principalmente pelos relatos verbais dos pacientes, mas, como a verbalização da criança pequena é geralmente escassa, foi necessária uma inovação técnica para favorecer uma comunicação mais significativa. (SIMON; YAMAMOTO, 2012, p.15)

Para Winnicot (1975), o brincar tende a favorecer o crescimento da criança, propiciando o relacionamento social e, acima de tudo, fundamental para a comunicação em processo de psicoterapia. É necessário existir um espaço potencial que una o mundo interno da criança com a realidade externa, só assim é possível que ela consiga se expressar nas brincadeiras de forma criativa.

Através do brincar podemos nos inteirar da realidade da criança, ela consegue se expressar e transmitir ao analista todas suas frustrações, fantasias, medos e sentimentos de desamparo, sendo este, foco desse trabalho, por exemplo, quando uma criança está em psicoterapia e no momento das brincadeiras o analista propõe a brincadeira com a família terapêutica, é observado que ali naquele momento a criança tende a repetir o seu contexto familiar, principalmente no que se refere à escolha dos personagens.

Todas as mudanças que ocorrem durante o desenvolvimento da criança, inclusive no momento em que ela se afasta, de alguma forma, da presença do objeto materno, ela experimenta o sentimento da ansiedade, o brinquedo pode ser uma possibilidade de a criança elaborar tais situações, uma vez que através do brincar que ela pode fazer a transição entre ambivalência com a mãe e a relação como o mundo externo (ABERASTURY, 1992).

Quando se refere à função do brincar, os autores Leitão e Cacciari (2017) trazem uma contribuição:

Contudo, quando falamos do brincar em psicanálise, não falamos de uma ludoterapia, mas de uma função do brincar, o qual não é um brincar qualquer, sem consequências ou que visa somente uma ab-reação, ou seja, a descarga emocional referente a algum trauma psíquico como função terapêutica principal. (LEITÃO; CACCIARI, 2017, p. 68)

Conclui-se que assim a criança por meio do brincar pode elaborar situações que the foram dolorosas e traumáticas, nesse sentido, essas situações serão projetadas no exterior, e isso será possível através dos jogos e brincadeiras. Além disso, o brincar proporciona para a criança diversos benefícios como, comunicação, desenvolvimento da criatividade e formação de vínculos com o meio externo.

Nesse contexto, Lima e Bernardi (2016) pontuam que Aberastury considera fundamental se atentar para o local em que serão realizados os atendimentos, o espaço deverá ser suficiente para a criança brincar livremente, de modo que ela consiga se expressar sem restrições. É necessário que os armários de brinquedos estejam ao acesso da criança e de maneira organizada. Esses materiais podem ser compostos de massinhas, fantoches, carrinhos, pincéis, lápis de cor e preto, papéis para desenho, entre outros.

Nesse contexto, é possível considerar que a brincadeira em setting terapêutico é de grande relevância para a criança e ao projetar sua realidade nas brincadeiras a mesma poderá lidar com suas questões internas e até mesmo elaborá-las, beneficiando de uma diminuição de sua dor e angústia.

Para Aberastury (1992), as identificações projetivas são determinantes no processo de elaboração. As crianças propendem a lançar transferências positivas e negativas para os brinquedos da forma com que aguçam ou aquietam sua ansiedade.

É necessário, que o analista esteja voltado para uma cuidadosa observação do momento em que a criança está brincando. Ao iniciar o processo de análise, a princípio o analista fica diante da demanda trazida pelos pais ou responsáveis, como objetivo de investigar a fundo o motivo no qual buscaram atendimento. Esse momento é muito importante para o processo. Buscar entender como foi à infância, o ambiente no qual a criança está inserida, sua rotina, ou seja, dados que possam colaborar no entendimento da demanda se faz imprescindível.

Quando falamos do brincar como recurso 
terapêutico, Winnicot enfatiza que deverá ocorrer um espaço potencial, que a criança consiga se desenvolver criativamente. Tanto o paciente quanto os analistas deverão estar implicados neste espaço que deverá ser investido de afeto a fim de que a brincadeira seja tão real quanto à realidade. (FRANCO, 2003)

Segundo Priszkulnik (1995), Maud Mannoni pontua a importância de escutar os pais em um primeiro momento, já que muitas vezes o relato deles contribuirá com a análise. Mas, é importante perceber se a fala dos pais está implicada no sintoma do filho ou os próprios pais que necessitam de uma escuta psicanalítica, nesse caso, é importante que os pais tenham seu próprio espaço de escuta.

Quando nos referimos ao processo de transferência, Aberastury (1982) enfatiza em sua obra que para Melanie Klein, é totalmente espontânea a transferência por parte da criança, e assim, ela deverá ser interpretada como negativa ou também positiva. Portanto, a criança projeta tanto no analista quanto nos brinquedos suas propensões de amor e destruição. Por isso durante os atendimentos com crianças é possível observar que ela posiciona o analista em variados papéis.

Para melhor compreender:

Nas personificações do jogo, observa-
se que muito rapidamente pode mudar
o objeto de bom em mau, de aliado em inimigo, e como
o analista assume e interpre $\neg$ ta os papéis hostis requeridos
pelo jogo, como também os positivos, existe um cons $\neg$ tante
progresso em direção a identificações mais bondosas e uma
maioraproximaçàrealidade(ABERASTURY, 1982,p.67).

É através do brinquedo que a criança tem a possibilidade de perder o medo de perigos de seu mundo interno (ABERASTURY, 1982). Segundo a autora, o jogo quando sugerido pelo analista ou escolhido livremente pela criança se torna parte de algum fato ou situação vivenciada pela criança, ou seja, provavelmente ela irá repetir de forma simbólica nos jogos algo de sua realidade.

\section{Consideraçoes Finais}

Diante de tudo que foi visto, pode-se pensar acerca da grande importância que é o brincar para a clínica com crianças. Além de promover a comunicação entre analista e paciente, o brincar se torna ferramenta indispensável para que o mesmo consiga elaborar situações que lhe foram traumáticas.

Destarte que não é apenas no setting terapêutico que os brinquedos são fundamentais, mas em todo o desenvolvimento da criança, principalmente quando por algum motivo o objeto materno se faz ausente. Nesse caso, discorremos que é cada vez mais comum a necessidade dos pais terem que se distanciar isso devido ao atual cenário contemporâneo em que os cuidados da criança passam bem mais cedo para creches ou algum outro cuidador.

Sendo assim, a criança faz uso do objeto transicional, para lidar com essa falta, podendo ser um brinquedo, pedaço de pano, ou algo que lhe passe certa sensação de segurança e aconchego. Todos os recursos psíquicos da criança são fundamentais no processo de elaboração das situações causadoras de angústia. Sendo assim, acreditamos que para a psicanálise, o período da infância é muito relevante para a constituição psíquica do sujeito, e dessa forma quando alguma situação adversa ocorre, ela tende a permanecer no psiquismo como alguma situação potencialmente traumática. Nesse caso, considera-se a possibilidade do brincar favorecer o processo de ressignificação e elaboração de tais situações que lhe causaram sentimento de desamparo.

\section{Referências}

ABERASTURY, A. A criança e seus jogos. Porto Alegre: Artmed, 1992.

Psicanálise da criança - teoria e técnica. 8.ed. Porto Alegre: Artes Médicas, 1982.

COSTA, T. Édipo. Rio de Janeiro: Zahar, 2010a.

Psicanálise com crianças. 3.ed. Rio de Janeiro: Zahar, 2010 b. LIMA, J. H. C. A.; BERNARDI, A. B. O brincar como um recurso terapêutico para crianças em saúde mental. 2016. Disponível em: http://www.uniedu. sed.sc.gov.br/wp-content/uploads/2016/02/Jenniffer-Haranda-ColomboAntunes-de-Lima.pdf. Acesso em: 20 set. 2019.

FRANCO, Sérgio de Gouvêa. O brincar e a experiência analítica. Ágora (Rio J.), Rio de Janeiro, v. 6, n. 1, p. 45-59, Junho, 2003. Disponível em: http://www.scielo.br/scielo.php?script=sci_arttext\&pid=S1516$14982003000100003 \& \operatorname{lng}=\mathrm{en} \& n \mathrm{~nm}=$ iso. Acesso em 20 Set. 2019.

LAPLANCHE, J.; PONTALIS. B. Vocabulário de Psicanálise. 4.ed. São Paulo: Martins Fontes, 2001.

LAURENTINO, M. C. S. ; MELO, V. B.O Brincar nas Perspectivas: Freudiana, Kleiniana e Winnicottiana. Psicologado. Edição 03/2015. Disponível em: https://psicologado.com.br/abordagens/psicanalise/obrincar-nas-perspectivas-freudiana-kleiniana-e-winnicottiana. Acesso em: 20 set. 2019.

LEITÃO, I.; CACCIARI, M. A demanda clínica da criança: uma psicanálise possível. Estilos da Clinica, v. 22, n. 1, p. 64-82, 12 jul. 2017. Disponível em:

http://www.revistas.usp.br/estic/article/view/121240/129954. Acesso em: 20 set. 2019.

LEVINZON, Gina Khafif. Recordar, repetir, elaborar e construir: a busca do objeto materno na análise de uma menina adotada. Rev. bras. psicanál, São Paulo, v. 44, n. 4, p. 155-164, 2010 .Disponível em http://pepsic.bvsalud.org/scielo.php?script $=$ sci arttext\&pid=S0486$641 \mathrm{X} 2010000400014 \& \operatorname{lng}=\mathrm{pt \& nrm}=\mathrm{iso}>$. Acesso em 20 set. 2019.

NASIO, J.C. Introdução às obras de Freud, Ferenczi, Groddeck, Klein, Winnicott, Dolto, Lacan. Rio de Janeiro: Zahar, 1995.

PRISZKULNIK, L.A criança e a psicanálise: o "lugar" dos pais no atendimento infantil. Psicol. USP, São Paulo, v. 6, n. 2, p. 95-102, 1995. Disponível em: $\quad$ http://pepsic.bvsalud.org/scielo.php?script=sci arttext\&pid=S1678$51771995000200006 \& \operatorname{lng}=$ pt\&nrm=iso. Acesso em 20 set. 2019.

RESSTEL, CCFP. Desamparo psíquico. In: Desamparo psíquico nos filhos de dekasseguis no retorno ao Brasil [online]. São Paulo: Editora UNESP, São Paulo: Cultura Acadêmica, 2015, pp. 87-104. ISBN 978-85-7983-674-9. 
Disponível em:

http://books.scielo.org/id/xky8j/pdf/resstel-9788579836749-07.pdf. Acesso em: 20 set. 2019.

SIMON, R. ; YAMAMOTO, K. Fundamentos teóricos do ludodiagnóstico. In: AFFONSO. R. M.L. Ludodiagnóstico - Uma investigação através do brinquedo. Porto Alegre: Artmed, 2012.

SOUZA, R. O. O mito do sentimento materno inato: Uma abordagem sobre a negligência e suas implicações para na sustentação interior. Rio de Janeiro: Letra Capital Editora, 2010

WINNICOTT, D.W. O brincar e a realidade. Rio de Janeiro: Imago, 1975. (Trabalho original publicado em 1971). 